\section{Catheter Ablation of Atrial Fibrillation and Thromboembolic Risk}

\section{To the Editor:}

Catheter ablation of atrial fibrillation (AF) is an effective therapy for the reduction of AF burden, improvement of symptoms and for quality of life. ${ }^{1}$ Although the thromboembolic (TE) risk seems to be increased post-ablation, ${ }^{2}$ observational and registry studies have demonstrated low annual rates of TE after AF catheter ablation, reaching event rates that are broadly comparable to those in patients without AF. 2,3

With great interest we read the article by Takigawa and coworkers $^{4}$ on the incidence of TE in 1,156 patients with paroxysmal AF undergoing catheter ablation. The authors report 9 cases of TE $(0.78 \%)$ in the whole study population, which represents a very low occurrence $(0.19 \%$ annually) of latephase TE. Furthermore, by analyzing independent predictors for stroke, only a $\mathrm{CHADS}_{2}$ score $\geq 2$ remained significantly associated with TE occurrence during follow-up.

We would like to congratulate the authors for their important study and concur with the main conclusion that TE after $\mathrm{AF}$ catheter ablation is rare. ${ }^{5}$ However, we have some comments based on observations from our own and other registries.

First and of clinical relevance, only strokes but not TIA or peripheral thromboembolism were reported in the current study, which is a somewhat incomplete picture and in contrast to previous reports. ${ }^{5,6}$ The first study reporting the association between late TE related to the AF catheter ablation was the study by Chao and colleagues. ${ }^{6}$ Although that Taiwanese group reported a much higher TE incidence than other studies, the main results were in accordance with our findings. ${ }^{5}$ The main difference between the current study ${ }^{4}$ and previous research are the missing data for TE prediction using the $\mathrm{CHA}_{2} \mathrm{DS}_{2}-$ VASc score, which use is recommended by current AF management guidelines in daily routine. ${ }^{7}$ As demonstrated by Chao et al and later confirmed in our study, the $\mathrm{CHA}_{2} \mathrm{DS}_{2}-$ VASc score was able to further differentiate TE risk in truly low- and high-risk strata in patients with low/intermediate $\mathrm{CHADS}_{2} \mathrm{O}_{-1}$. This finding is of clinical importance, because the association between $\mathrm{CHADS}_{2} \geq 2$ presented by Takigawa and coworkers ${ }^{4}$ reveals high-risk patients and means no doubt in the anticoagulation need before and after invasive AF treatment. In contrast, in patients with low risk for TE the need for anticoagulation after AF ablation is controversial. Therefore, it would be very interesting to ascertain how many patients with truly low $\mathrm{CHA}_{2} \mathrm{DS}_{2}$-VASc score suffered late-phase TE in current study. ${ }^{4}$

Second, current AF management guidelines ${ }^{7}$ recommend oral anticoagulation for 3-6 months after AF catheter ablation and then dependent on the $\mathrm{CHA}_{2} \mathrm{DS}_{2}-\mathrm{VASc}$ score but not rhythm outcomes. Importantly, freedom from AF has been found as the strongest predictor of stroke-free survival. ${ }^{8}$ Although the association between TE and AF recurrence did not reach significance in our study, ${ }^{5}$ our results demonstrated a 4 .2-fold risk for TE in patients with AF recurrence in univariable analysis. This finding was inconclusive in the current study, ${ }^{4}$ in which AF recurrence was only weakly associated with late-phase TE (hazard ratio $3.79, \mathrm{P}=0.06$ ), revealing a similar risk. In our study the $\mathrm{CHA}_{2} \mathrm{DS}_{2}-\mathrm{VASc}$ score had the best predictive value for TE in the subgroup with AF recurrence, which was superior to the $\mathrm{CHADS}_{2}(\mathrm{P}=0.022)$ score.

In summary, stroke risk stratification scores are also useful in patients undergoing catheter ablation. However, recent studies demonstrated a complex relation between conventional risk factors, anticoagulation regimen and rhythm outcomes following AF catheter ablation. Recent data suggest that highrisk patients identified by risk scores would need optimized anticoagulation through intensified oral anticoagulation and/ or intensified rhythm control, while low risk patients remain challenging. Further studies are still needed to address those issues.

\section{Disclosures}

None.

\section{References}

1. Calkins H, Kuck KH, Cappato R, Brugada J, Camm AJ, Chen SA, et al. 2012 HRS/EHRA/ECAS Expert Consensus Statement on Catheter and Surgical Ablation of Atrial Fibrillation: Recommendations for patient selection, procedural techniques, patient management and follow-up, definitions, endpoints, and research trial design. Europace 2012 ; 14: 528-606.

2. Oral H, Chugh A, Ozaydin M, Good E, Fortino J, Sankaran S, et al. Risk of thromboembolic events after percutaneous left atrial radiofrequency ablation of atrial fibrillation. Circulation 2006; 114: 759765 .

3. Bunch TJ, Crandall BG, Weiss JP, May HT, Bair TL, Osborn JS, et al. Patients treated with catheter ablation for atrial fibrillation have long-term rates of death, stroke, and dementia similar to patients without atrial fibrillation. J Cardiovasc Electrophysiol 2011; 22: $839-845$.

4. Takigawa M, Takahashi A, Kuwahara T, Takahashi Y, Okubo K, Nakashima E, et al. Late-phase thromboembolism after catheter ablation for paroxysmal atrial fibrillation. Circ J 2014; 78: 2394-2401.

5. Kornej J, Hindricks G, Kosiuk J, Arya A, Sommer P, Husser D, et al. Renal dysfunction, stroke risk scores (CHADS2, CHA2DS2VASc, and R2CHADS2), and the risk of thromboembolic events after catheter ablation of atrial fibrillation: The Leipzig Heart Center AF Ablation Registry. Circ Arrhythm Electrophysiol 2013; 6: 868 874.

6. Chao TF, Lin YJ, Tsao HM, Tsai CF, Lin WS, Chang SL, et al. CHADS(2) and CHA(2)DS(2)-VASc scores in the prediction of clinical outcomes in patients with atrial fibrillation after catheter ablation. J Am Coll Cardiol 2011; 58: 2380-2385.

7. Camm AJ, Lip GY, De Caterina R, Savelieva I, Atar D, Hohnloser $\mathrm{SH}$, et al. 2012 focused update of the ESC Guidelines for the management of atrial fibrillation: An update of the 2010 ESC Guidelines for the management of atrial fibrillation: Developed with the special contribution of the European Heart Rhythm Association. Eur Heart J 2012; 33: 2719-2747.

8. Hunter RJ, McCready J, Diab I, Page SP, Finlay M, Richmond L, et al. Maintenance of sinus rhythm with an ablation strategy in patients with atrial fibrillation is associated with a lower risk of stroke and death. Heart 2010; 98: 48-53.

Jelena Kornej, MD

Gerhard Hindricks, MD

Gregory YH Lip, MD

Andreas Bollmann, MD, PhD

Department of Electrophysiology, Heart Center Leipzig,

Leipzig (J.K., G.H., A.B.), Germany; Centre for Cardiovascular Sciences, University of Birmingham, Birmingham (G.Y.H.L.), UK

(Released online January 7, 2015) 